\title{
NOTA SOBRE A OCORRENCIA DE LEISHMANIOSE TEGUMENTAR AMERICANA NA SERRA DA CANTAREIRA, SÃO PAULO, SP, BRASIL *
}

\author{
Nelson Guimarães Proença** \\ Helena Muller **
}

\begin{abstract}
RSPUB9/448
Proença, N. G. \& Muller, H. Nota sobre a ocorrência de leishmaniose tegumentar americana na Serra da Cantareira, São Pauto, SP, Brasil. Rev. Saúde públ., S. Paulo, 13:56-9, 1979.

Resumo: Relata-se a ocorrência de um pequeno surto de leishmaniose tegumentar americana, na Serra da Cantareira, São Paulo, SP, Brasil. Foram feitas considerações sobre a persistência de nichos de leishmaniose no Estado de São Paullo.
\end{abstract}

Unitermos: Leishmaniose tegumentar, S. Paulo, Brasil. Epidemia, S. Paulo, SP, Brasil.

I N T RODUÇ Ā O

A leishmaniose tegumentar americana é doença que ocorre principalmente nas zonas de neocolonização, onde chega a adquirir destacada importância, como problema de dermatologia sanitária. Na medida em que essas novas zonas vão sendo integradas ao processo de desenvolvimento, a moléstia tende a declinar e depois a desaparecer.

Fato curioso, entretanto, é a persistência de pequenos focos silvestres, onde a leishmaniose persiste, em nichos naturais, onde o parasita circula entre os roedores silvestres $e$ os insetos transmissores, sem a participação do ser humano. As matas, onde este fato ocorre, podem ser de muito pequeno porte, situando-se ao lado mesmo de zonas urbanizadas, sem que haja a ocorrência de casos clínicos.
Em determinado momento o processo de urbanização exige a derrubada dessas pequenas matas e, nessas condiçóes, rompese 0 equilibrio em que se encontrava 0 ecossistema. Como conseqüência - e por um momento - aparecem casos de leishmaniose, onde há muitas décadas ela era considerada completamente extinta.

$\mathrm{Na}$ Capital de São Paulo, em torno de 1960, surgiram numerosos loteamentos na zona sul da cidade, tendo sido então abatidas pequenas matas ali existentes. Em conseqüência, várias comunicaçōes sobre a ocorrência de casos autóctones de leishmaniose tegumentar americana apareceram na literatura médica $1,2,5$.

Desde o principio da década de 70 , a urbanização das áreas adjacentes à cidade de São Paulo transpôs o espigão da Serra

* Trabalho realizado no Centro Dermatológico de Santana. Rua Dr. Cesar, 62 - 02013 São Paulo - SP - Brasil.

* Da Faculdade de Ciências Médicas da Santa Casa de São Paulo, Rua Cesário Motta Jr., 112 - 01221 - São Paulo - SP - Brasil. 
PROENÇA, N. G. \& MULLER, H. Nota sobre a ocorrência de leishmaniose tegumentar americana na Serra da Cantareira, São Paulo, SP, Brasil. Rev. Saúde públ., S. Paulo, 13 $56-9,1979$.

da Cantareira, avançando em direção ao norte. Ficou-se então na expectativa de que ali pudesse ocorrer o mesmo que na zona sul, quinze anos antes. $E$ isto, de fato, foi novamente verificado.

No presente trabalho, comunicamos uma microepidemia observada no princípio de 1978, em loteamento de alto padrão, na Serra da Cantareira. (Fig. 1).

Em 23-05-78 compareceu à consulta um homem de 77 anos, branco, com lesão ulcerada do pavilhão auricular esquerdo, fortemente infectada, supurativa e crostosa. Havia reação inflamatória que conferia aspecto erisipelatoso à hemiface esquerda (Fig. 2). A suspeita foi de uma piodermite. Após 13 dias compareceu à consulta seu filho de 54 anos, com típica úlcera leishmaniótica no antebraço direito (Fig. 3).

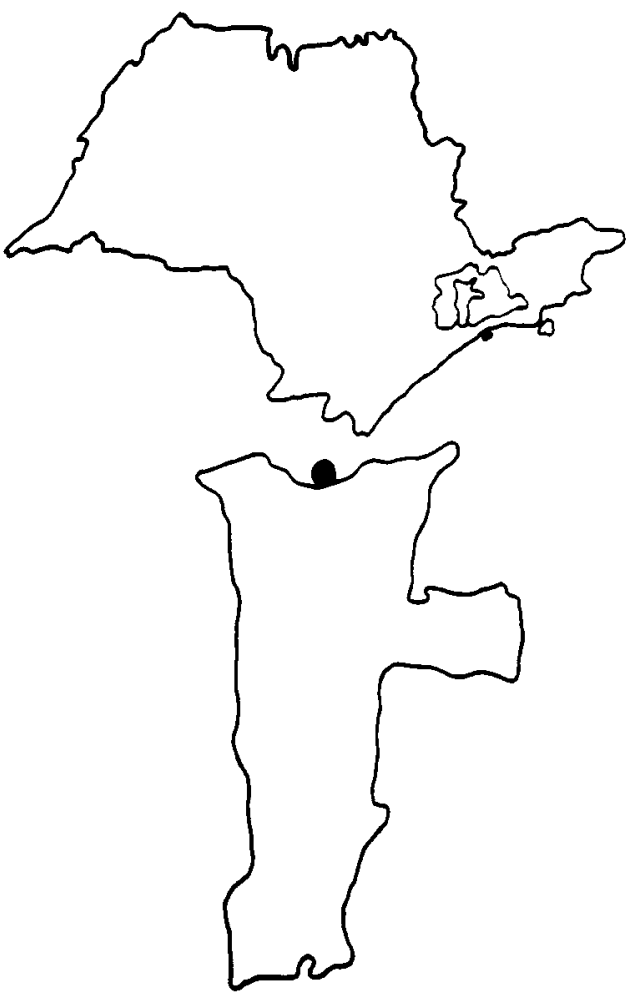

Fig. 1 - Mapa do município de São Paulo, localizando a região onde ocorreu o surto de leishmaniose tegumentar americana.

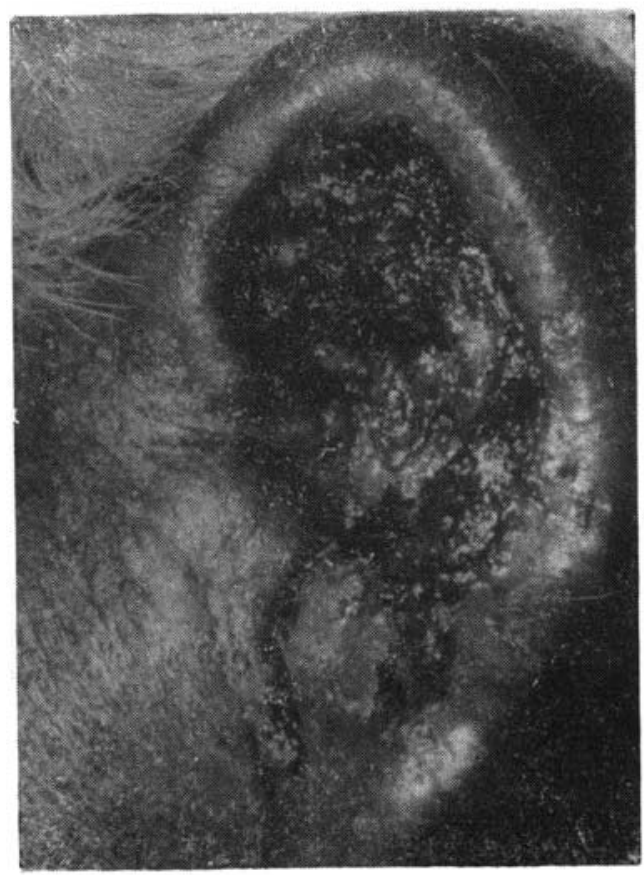

Fig. 2 - Leishmaniose do pavilhão auricular

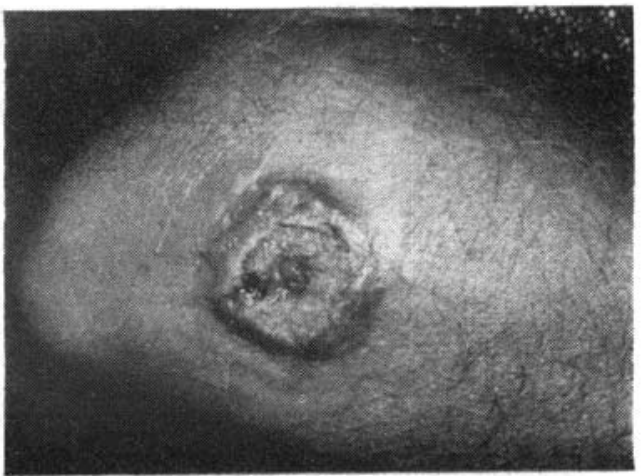

Fig. 3 - Leishmaniose do antebraço

Foi feito então o diagnóstico retrospectivo de seu pai. A nosso pedido, os pacientes procuraram detectar outros casos entre seus vizinhos, descobrindo-se assim, um terceiro doente, que foi também examinado. Os dados clínicos fundamentais, sobre os três casos, estão reunidos na Tabela. 
PROENÇA, N. G. \& MULLER, H. Nota sobre a ocorrência de leishmaniose tegumentar americana na Serra da Cantareira, São Paulo, SP, Brasil. Rev. Saúde públ., S. Paulo, 13: $56-9,1979$.

Foi realizada a intradermorreação de Montenegro, segundo a técnica consagrada, utilizando-se antígeno produzido pelo Instituto Adolfo Lutz, de São Paulo. Dos três pacientes foi tomada biópsia de lesão ulcerosa, bem próxima à sua borda, tendo sido preparados cortes finos corados pela hematoxilina-eoxina.

Todos os doentes tiveram a intradermorreação de Montenegro positiva (de 0,8 a $1,2 \mathrm{~cm})$. A histopatologia mostrou, nos três casos, um processo inflamatório crônico inespecífico, predominantemente linfoplasmocitário. A pesquisa de leishmanias foi positiva em 1 dos 3 doentes.
Todos foram tratados com antimonial pentavalente (glucantime), duas ampolas ao dia, por via intramuscular, durante 10 dias. Após descanso repetiu-se uma segunda série. A cura foi conseguida mesmo antes de completarem o tratamento.

O loteamento Parque Petrópolis é o mais antigo da encosta norte da Serra da Cantareira, datando de 1957. As residências onde ocorreram os casos são de alto padrão e foram construidas no fim da década de 60. Ambas estão situadas a uma altitude de 800 metros sobre o nivel do mar. Possuem jardins bem cuidados, com arborização ornamental. Estão separadas entre

T A B E L A

Ocorrencia de pequeno surto de leishmaniose tegumentar americana na periferia da cidadt de São Paulo (Serra da Cantareira).

\begin{tabular}{|c|c|c|c|c|c|}
\hline Caso & $\begin{array}{c}\text { Idade } \\
\text { sexo } \\
\text { cor }\end{array}$ & $\begin{array}{l}\text { Mês do } \\
\text { início }\end{array}$ & $\begin{array}{l}\text { Data do } \\
\text { 10 exame }\end{array}$ & Localização & $\begin{array}{l}\text { Aspecto } \\
\text { Clínico }\end{array}$ \\
\hline 01 & $77 / \mathrm{M} / \mathrm{B}$ & $03 / 78$ & $23 / 05 / 78$ & Orelha $\mathrm{E}$. & Ûlcera infectada \\
\hline 02 & $54 / \mathrm{M} / \mathrm{B}$ & $03 / 78$ & $05 / 06 / 78$ & Antebraço D. & Ûlcera típica \\
\hline 03 & $36 / \mathrm{M} / \mathrm{B}$ & $01 / 78$ & $05 / 08 / 78$ & Perna D. & $\begin{array}{l}\text { Úlceras vegetantes, } \\
\text { de superfície } \\
\text { verrucosa. }\end{array}$ \\
\hline
\end{tabular}

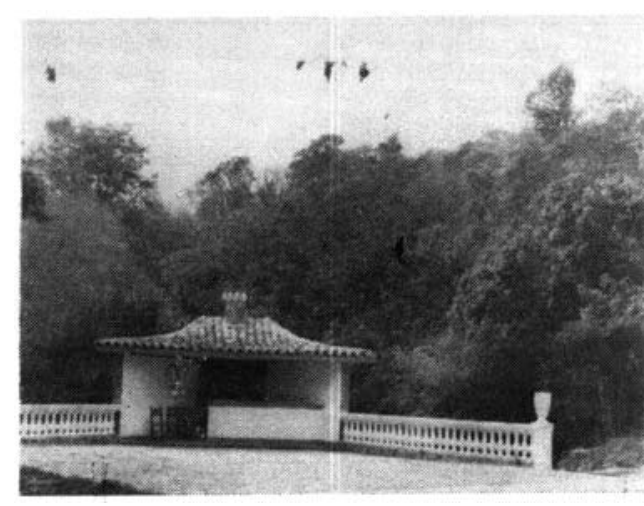

Fig. 4 - Vista do ambiente em que ocorreu a microepidemia; em primeiro plano jardim de residência de alto padrão, nos fundos do qual se encontra a pequena mata onde provavelmente a parasitose encontra-se em nichos. si por uma distância de $150 \mathrm{~m}$, ocupada por pequena mata de segunda formação, com aproximadamente 3 alqueires paulistas de área (Figura 4). Em novembro e dezembro de 1977 foi derrubada parte desta mata, a uma distância aproximada de $150 \mathrm{~m}$ das citadas casas. $O$ motivo da derrubada foi a formação de um novo loteamento quando foram feitos os arruamentos necessários. Os casos apareceram com intervalo de 2 a 5 meses após a derrubada da mata.

\section{COMENTÁRIOS}

Nas últimas décadas declinou, de modo progressivo, a incidência de leishmaniose tegumentar, no Estado de São Paulo. Das regiōes antigas, continuam sendo frequien- 
PROENÇA, N. G. \& MULLER, H. Nota sobre a ocorrência de leishmaniose tegumentar americana na Serra da Cantareira, São Paulo, SP, Brasil. Rev. Saúde pübl, S. Paulo, 13: $56-9,1979$.

temente descritos novos casos, na região litorânea do Sul do Estado, que corresponde ao Vale do Ribeira ${ }^{4}$; nessa área, os números são suficientemente significativos, permitindo aceitar que ali ainda exista uma endemia leishmaniótica. Além desse foco, apenas tem algum interesse epidemiológico a leishmaniose que ocorre nas fronteiras de São Paulo com Mato Grosso.

No mais, o que tem havido são casos esporádicos, que ocorrem praticamente em todo o Estado de São Paulo, mas em números desprovidos de significação. Assistimos então a uma mudança nas características epidemiológicas da leishmaniose, neste Estado. Antes, era moléstia das áreas virgens, aparecendo de modo francamente epidêmico entre os colonizadores dessas àreas. Hoje é moléstia que ocorre de modo esporádico, em todo o Estado.

Esta verificação leva a uma interessante conclusão: o ecossistema em que se per- petua a Leishmania braziliensis pode ter proporções muito pequenas, ficando abrigado mesmo em matas diminutas, sem atingir o ser humano que mora em suas adjacências. Estes pequenos nichos parecem persistir em todo o Estado, mesmo junto aos mais desenvolvidos centros urbanos, como é exemplo o ocorrido na Capital paulista.

Qual seria a variedade desta Leishmaniose, que persiste em focos "residuais"? Forattini 3 , estudando o comportamento epidemiológico dos pequenos focos descritos na Capital paulista, há 20 anos atrás, concluiu que se tratava da variedade dita "leishmaniose centro e sul-americana" e não da "leishmaniose cutâneo-mucosa". Aliás, esse Autor crê ainda que os focos do litoral sul de São Paulo (zona de Ribeira do lguape) pertençam também a esta variedade.

RSPUB9/448

Proença, N. G. \& MUller, H. [A microepidemic outbreak of american mucocutaneous leishmaniasis in S. Paulo, Brazil.J Rev. Saúde públ., S. Paulo, 13: $56-9,1979$.

ABSTRACT: A microepidemic outbreak of american mucocutaneous leishmaniasis occurred at the beginning of 1978 in the "Serra da Cantareira", S. Paulo, Brazil. The persistence of some of the niche is commented on.

UNITERMS: Leishmaniasis, mucocutaneous, S. Paulo, Brazil. Disease outbreaks, S. Paulo, Brasil.

\section{REFERENCIAS BIBLIOGRAFICAS}

1. Almeida Neto, E. de \& PROENÇA, N. Ocorrência de leishmaniose tegumentar americana autóctone no município de São Paulo e adjacências. Rev. paul. Med., 56:374-9, 1960.

2. FORATTINI, O. P. \& OLIVEIRA, O. de Um foco de leishmaniose tegumentar na zona sul de São Paulo, Brasil. Arq. Fac. Hig. S. Paulo, 11:23-34, 1957.

3. FORATTINI, O. P. Entomologia médica. São Paulo, Ed. Edgard Blucher/Ed. USP, 1973. v. 4, p. 591.
4. FORATtiNI, O. P. et al. Nota sobre leishmaniose tegumentar no litoral sul do Estado de São Paulo, Brasil. Rev. Saúde públ., S. Paulo, 7:447-52, 1973.

5. PESSOA, S. B. Classificação das leishmanioses e das espécies do gênero Leishmania. Arq. Hig., S. Paulo, 26:41$50,1961$.

Recebido para publicação em 16,10/1978 Aprovado para publicąão em 09,11/1978 